\title{
Suppressive Effects of Bifidobacterium breve Strain M-16V on T-Helper Type 2 Immune Responses in a Murine Model
}

\author{
Yumi Inoue, Noriyuki Imabuchi, Jin-zhong Xiao, ${ }^{*}$ Tomoko Yaeshima, and Keiji Iwatsuki \\ Food Science and Technology Institute, Morinaga Milk Industry Co., Ltd.; 5-1-83 Higashihara, Zama, Kanagawa \\ 228-8583, Japan. Received November 4, 2008; accepted January 15, 2009
}

\begin{abstract}
The Bifidobacterium breve M-16V strain has previously been shown to be effective in infants in improving the symptoms of allergic hypersensitivity to cow's milk and atopic dermatitis. In the current study, we investigated the effect of an oral administration of M-16V on immunoglobulin (Ig) E production in BALB/c mice. Live M-16V was orally administered to ovalbumin (OVA)-immunized mice for 3 weeks at a dose level of $5 \times 10^{8}$ colony-forming unit (cfu) $/ 0.5 \mathrm{ml} / \mathrm{d} /$ animal. While M-16V treatment significantly reduced the serum levels of total IgE, OVA-specific IgE and OVA-specific IgG1, as compared to controls, it did not affect the serum level of OVA-specific IgG2a. In M-16V-administered mice, there was a significant decrease in the serum OVA-specific IgG1/IgG2a ratio. In addition, while ex vivo production of interleukin (IL)-4 by the splenocytes from M-16V-administered mice was significantly lower as compared to controls, there was no difference in the production of gamma-interferon (IFN- $\gamma$ ) and IL-10. We also examined the effect of M-16V on cytokine and IgE production from OVA-sensitized splenocytes via restimulation with OVA in vitro. While M-16V suppressed OVA-induced total IgE and IL-4 production and induced secretion of IFN- $\gamma$ and IL-10 in a dose-dependent manner, it was not able to induce IL-12. We concluded that oral administration of M-16V suppressed the T-helper type (Th) 2 immune response and IgE production and modulated the systemic Th1/Th2 balance, and which was at least partially independent of the Th1 cytokine induction. These results suggest that M-16V may potentially have an antiallergic activity.
\end{abstract}

Key words Bifidobacterium breve M-16V; probiotic; immunoglobulin E; ovalbumin; allergic disease

Type I allergies such as allergic rhinitis and hay fever are caused by characteristic immune responses to allergens, primarily mediated by T-helper type (Th) 2 cells. ${ }^{1,2}$ Th2 cells synthesize high levels of interleukin (IL)-4, IL-5 and IL-13, which leads to the production of allergen-specific immunoglobulin (Ig) $\mathrm{E}$ and the release of histamine and leukotriene from mast cells. ${ }^{2)}$ Conversely, Th1 cells suppress Th2 immune responses by secreting gamma-interferon (IFN$\gamma)$. IL-4 induces the class switching to IgG1 and IgE, whereas IFN- $\gamma$ is involved in the IgG2a class switching. ${ }^{3)}$ Therefore, the estimation of IgE production and Th1/Th2 cytokine balance is important in the study of type I allergic disorders. ${ }^{4,5)}$

Probiotics are defined as "live microorganisms, which when administered in adequate amounts confer a health benefit to the host" (FAO/WHO, 2002). Lactic acid bacteria, such as lactobacilli and bifidobacteria are among the best known probiotic candidates. In numerous human trials, the intake of probiotics, such as lactobacilli and bifidobacteria, has been reported to prevent several allergic diseases. ${ }^{6-11)}$ The potential benefit of probiotic bacteria in the modulation and regulation of the immune response has also been reported in both in vitro and in animal studies. ${ }^{12-19)}$

Bifidobacterium breve $\mathrm{M}-16 \mathrm{~V}$ is a probiotic strain that was isolated from fecal sample of a healthy baby. It has been previously shown that administration of $\mathrm{M}-16 \mathrm{~V}$ in infants with hypersensitivity to cow's milk and atopic dermatitis exhibit significantly improved allergic symptoms. ${ }^{20,21)} \mathrm{M}-16 \mathrm{~V}$ administration is associated with a significant increase in the proportion of bifidobacteria and a decrease in the proportion of aerobic bacteria found in the fecal microbiota, although no correlation has been noted between changes in the fecal microbiota and the decrease in the cutaneous symptom score. ${ }^{20,21)}$ Therefore, further investigations on the mecha- nism of M-16V's antiallergic activity needs to be undertaken.

In the present study, we evaluated the effect of M- $16 \mathrm{~V}$ on IgE production and on the Th1/Th2 balance in our allergy model that uses ovalbumin (OVA)-immunized mice with elevated serum IgE levels.

\section{MATERIALS AND METHODS}

Mice and Bacteria Six-week-old male BALB/c mice were purchased from Charles River Japan (Yokohama, Japan). The mice were housed in aluminum cages at room kept at $22 \pm 2{ }^{\circ} \mathrm{C}$ and $55 \pm 15 \%$ humidity, on a $12 \mathrm{~h}$ light/dark cycle under specific-pathogen-free conditions. The mice were fed a standard diet (F-2, Oriental Yeast, Tokyo) and allowed free access to water throughout the experimental period. All animal experiments were performed according to the guidelines of the Japanese Prime Minister's Office (no. 6, March 27, 1980).

Bifidobacterium breve $\mathrm{M}-16 \mathrm{~V}$ was obtained from a stock culture of the Morinaga Culture Collection (Morinaga Milk Industry Co., Ltd., Zama, Japan). Lactobacillus rhamnosus ATCC53103 (LGG) and Streptococcus thermophilus ATCC19258 (STH) were obtained from the American Type Culture Collection (ATCC; Manassas, VA, U.S.A.). M-16V and ATCC53103 were cultured for $16 \mathrm{~h}$ at $37^{\circ} \mathrm{C}$ in Lactobacilli-MRS broth (Difco, Detroit, MI, U.S.A.). ATCC19258 was cultured for $16 \mathrm{~h}$ at $37^{\circ} \mathrm{C}$ in M17 broth (Difco). Bacterial cells were collected by centrifugation, washed twice with phosphate-buffered saline (PBS), and then washed twice with sterile distilled water. The organisms were lyophilized and suspended in PBS at $10 \mathrm{mg} / \mathrm{ml}$ and then killed by heating the solution to $100^{\circ} \mathrm{C}$ for $30 \mathrm{~min}$. The stock suspensions which contained approximately $2 \times 10^{10}, 1 \times 10^{10}$, and $3 \times 10^{10}$ cells $/ \mathrm{ml}$ for M-16V, LGG and STH, respectively, 
were stored at $-80{ }^{\circ} \mathrm{C}$ until use.

Oral Administration of Live Bacteria The mice $(n=8$ per group) were intraperitoneally injected with $1 \mu \mathrm{g}$ of OVA (grade V; Sigma, St. Louis, MO, U.S.A.) absorbed on $2 \mathrm{mg}$ of $\mathrm{Al}(\mathrm{OH})_{3}$ on days 0 and 14 . Mice were orally given live M$16 \mathrm{~V}$, which was a commercial preparation from Morinaga Milk Industry Co., Ltd., starting on day 0 and continuing until day 21 at a dose level of $5 \times 10^{8}$ colony-forming unit (cfu) $/ 0.5 \mathrm{ml} / \mathrm{d} /$ animal. As a control, $0.5 \mathrm{ml}$ of PBS was administered to mice. Sera were collected and single-cell suspensions of the splenocytes were prepared on day 21. Subsequently, the serum levels of total $\mathrm{IgE}$ and OVA-specific $\operatorname{IgE}, \operatorname{IgG} 1$ and $\operatorname{IgG} 2 \mathrm{a}$ were measured. Splenocytes $(2.5 \times$ $10^{6}$ cells $\left./ \mathrm{ml}\right)$ were cultured with $100 \mu \mathrm{g} / \mathrm{ml}$ OVA in $0.5 \mathrm{ml}$ RPMI 1640 medium (Invitrogen, Grand Island, NY, U.S.A.) supplemented with $10 \%$ fetal bovine serum, 100 units $/ \mathrm{ml}$ penicillin and $100 \mu \mathrm{g} / \mathrm{ml}$ streptomycin in 48-well flat bottom culture plates at $37^{\circ} \mathrm{C}$ in $5 \% \mathrm{CO}_{2}$. Supernatants were collected on day 7 and stored at $-80^{\circ} \mathrm{C}$ until determination of the cytokine concentrations.

Cell Cultures for OVA-Induced IgE and Cytokine Production OVA-immunized BALB/c splenocytes were prepared as described by Shida et al. ${ }^{13)}$ with some modifications. Mice were injected intraperitoneally with $50 \mu \mathrm{g}$ of OVA absorbed on $2 \mathrm{mg}$ of $\mathrm{Al}(\mathrm{OH})_{3}$ gel. After $10 \mathrm{~d}$, splenocytes were prepared as a single-cell suspension $\left(2.5 \times 10^{6}\right.$ cells $\left./ \mathrm{ml}\right)$ from the immunized mice and cultured with $100 \mu \mathrm{g} / \mathrm{ml}$ OVA in the absence or presence of heat-killed bacteria $(0.1-10 \mu \mathrm{g} / \mathrm{ml})$ in 48 -well flat bottom culture plates at $37^{\circ} \mathrm{C}$ in $5 \% \mathrm{CO}_{2}$. Supernatants were collected on day 2 for IL-10, on day 7 for IL4, IFN- $\gamma$, IL-12p70 and transforming growth factor (TGF)- $\beta$ and on day 14 for $\operatorname{IgE}$ determination and then stored at $-80{ }^{\circ} \mathrm{C}$ until measurements.

Determination of Cytokines and Immunoglobulins Total IgE was measured using a commercial ELISA kit (Bethyl Laboratories, Inc., Montgomery, TX, U.S.A.). Cytokines (IFN- $\gamma$, IL-4, IL-10, IL-12p70 and TGF- $\beta$ ) were also quantified using commercial ELISA kits (R\&D Systems, Minneapolis, MN, U.S.A.) according to the manufacturer's instruction. OVA-specific IgE, IgG1 and $\operatorname{IgG} 2$ a were evaluated by ELISA in accordance with the methods of Sato et $a l .{ }^{22)}$ The standard serum for the OVA-specific immunoglobulin assays was obtained from serum of mice immunized with three intraperitoneal injections of OVA absorbed on $\mathrm{Al}(\mathrm{OH})_{3}$ gel at the intervals of 1 week. ${ }^{13)}$ The titers of the OVA-specific IgE, IgG1 and IgG2a in standard serum were arbitrary taken to be 10000 units/ml and the titers of sample serum were expressed as the relative value compared with standard serum. ${ }^{13)}$ As an index of systemic Th1/Th2 balance, ratios of individual OVA-specific IgG1 levels/OVA-specific IgG2a levels were calculated.

Statistical Analysis Experimental data are expressed as mean \pm S.D. Data were considered significantly different when the $p$ value was $<0.05$ as determined by Student's $t$-test for comparisons of 2 groups or non-repeated measures ANOVA followed by Bonferroni test for multiple comparisons with controls.

\section{RESULTS AND DISCUSSION}

Effect of Oral Administration of M-16V on the Serum Levels of Immunoglobulins and ex Vivo Cytokine Production by Splenocytes in OVA-Immunized Mice In preliminary experiments, oral administration of live $\mathrm{M}-16 \mathrm{~V}$ at $5 \times 10^{7}, 5 \times 10^{8}$ and $5 \times 10^{9} \mathrm{cfu} / 0.5 \mathrm{ml} / \mathrm{d} /$ animal for 3 weeks was found to suppress the serum total IgE level in a dose-dependent manner (data not shown). In the present experiment, oral administration of $\mathrm{M}-16 \mathrm{~V}$ at $5 \times 10^{8} \mathrm{cfu} / 0.5 \mathrm{ml} / \mathrm{d} / \mathrm{animal}$ significantly reduced the serum levels of total IgE, OVAspecific IgE and OVA-specific IgG1 in the OVA-immunized mice as compared to the controls (Figs. 1a-c). However, the serum level of OVA-specific IgG2a was not affected by the ingestion of M-16V (Fig. 1d). In addition, the serum $\mathrm{IgG} 1 / \mathrm{IgG} 2 \mathrm{a}$ ratio was significantly decreased in the mice administered $\mathrm{M}-16 \mathrm{~V}$ as compared to the ratio seen in the controls (Fig. 1e). Furthermore, while ex vivo production of IL-4 by the splenocytes from the mice administered M-16V was significantly lower than that of the controls, there was no dif-
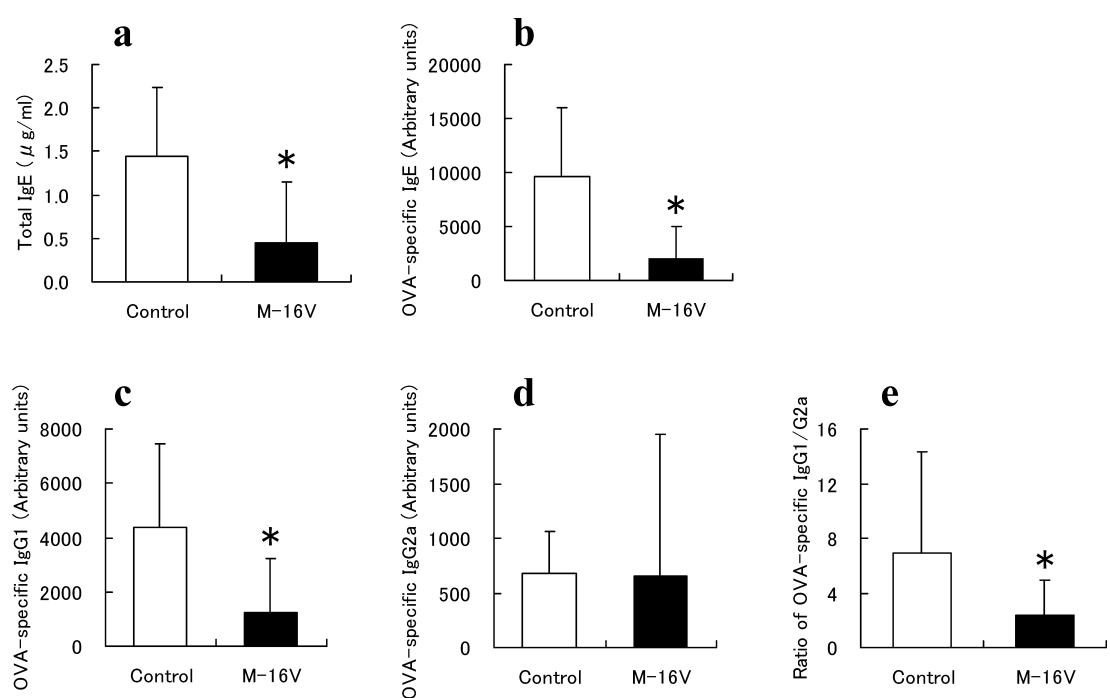

Fig. 1. Effects of Oral Administration of Bifidobacterium breve M-16V on the Serum Levels of IgE and IgG in OVA-Immunized Mice

Mice were intraperitoneally injected with OVA absorbed on $\mathrm{Al}(\mathrm{OH})_{3}$ gel on days 0 and 14 . Live M- $16 \mathrm{~V}$ was given orally to mice at $5 \times 10^{8}$ cfu/ $0.5 \mathrm{ml} / \mathrm{d} / \mathrm{animal}$ from day 0 to day 21. Sera were collected on day 21, with the levels of total IgE (a), OVA-specific IgE (b), IgG1 (c) and IgG2a (d) determined by ELISA. Each column represents the mean \pm S.D. of eight animals. Significant differences as compared to control $(* p<0.05)$ were tested by a Student's $t$-test. 


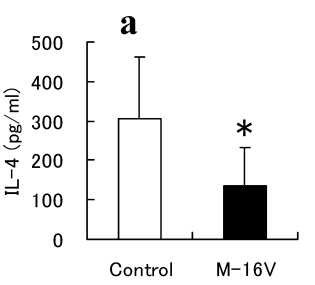

c

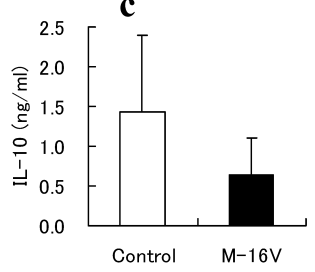

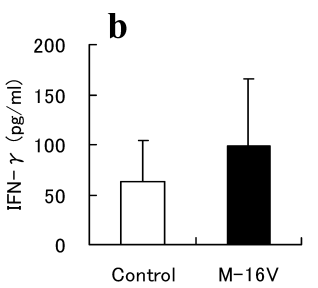

d

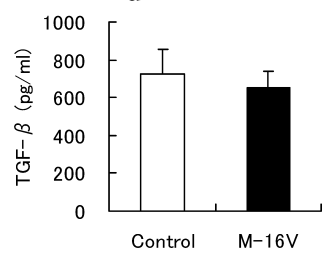

Fig. 2. Effect of Oral Administration of Bifidobacterium breve M-16V on ex Vivo Cytokine Production by Splenocytes

Immunization and administration of $\mathrm{M}-16 \mathrm{~V}$ were performed as has been described in Fig. 1. Single-cell suspensions of the splenocytes $\left(2.5 \times 10^{6} \mathrm{cells} / \mathrm{ml}\right)$ were prepared on day 21 and cultured with $100 \mu \mathrm{g} / \mathrm{ml}$ OVA. Supernatants were collected on day 7 , with the concentrations of IL- 4 (a), IFN- $\gamma$ (b), IL-10 (c) and TGF- $\beta$ (d) determined by ELISA. Each column represents the mean \pm S.D. of eight animals. Significant differences as compared to control $(* p<0.05)$ were tested by a Student's $t$-test.

ference noted in the production of IFN- $\gamma$, IL-10 and TGF- $\beta$ (Fig. 2). In both groups, the IL-12p70 levels were below the detection limit and thus, could not be detected. These results indicate that oral administration of $\mathrm{M}-16 \mathrm{~V}$ functioned by suppressing the Th2 immune response and IgE production without inducing the Th1 response.

Several previous reports have demonstrated the effects of the oral feeding of probiotic strains on the suppression of $\operatorname{IgE}$ and IL-4 production in animal models. ${ }^{12,15-19)}$ Among the studies that involved lactobacilli, oral feeding was shown to enhance the ex vivo Th1 cytokine production ${ }^{12,16)}$ and induce regulatory cytokines such as IL-10 and/or TGF- $\beta^{17,18)}$ by the splenocytes or by the Peyer's patch (PP) cells. These results suggest that with regard to the suppression of the Th2 immune response and $\mathrm{IgE}$ production, there may be different mechanisms for different probiotic strains. Bifidobacteria are the major components of the human intestinal microbiota. As probiotic agents, bifidobacteria have been studied for their efficacy in the prevention and treatment of a broad spectrum of animal and/or human disorders, such as constipation, colonic transit disorders, intestinal infections, colonic cancer and allergic diseases. However, to the best of our knowledge, only a few studies have examined the antiallergic activity of bifidobacteria. Ohno et al. demonstrated that oral administration of Bifidobacterium bifidum G9-1 significantly lowered the serum levels of OVA-specific IgE but did not affect the levels of OVA-specific IgG1 and IgG2a. ${ }^{15)}$ However, this strain was not able to induce IL-12p70 and IFN- $\gamma$ production in the splenocytes in vitro. ${ }^{15)}$ In the present study, oral administration of M-16V significantly lowered the serum levels of total IgE, OVA-specific IgE and ex vivo production of IL-4 by the splenocytes, but did not affect the ex vivo production of IFN- $\gamma$ and IL-10 by splenocytes. These results provided additional evidence that bifidobacteria are able to suppress the Th2 immune response and $\operatorname{IgE}$ production in allergic animal models without remarkable induction of the Th1 cytokine. Furthermore, our results also clearly showed that oral administration of M-16V significantly lowered the serum lev- els of OVA-specific IgG1 (Th2-associated), although there was no marked effect on OVA-specific IgG2a (Th1-associated). These findings are consistent with the pattern for the ex vivo cytokine production by the splenocytes (Fig. 2), and indicate that oral M-16V feeding modulates the systemic Th1/Th2 balance.

Effects of M-16V on Cytokine and IgE Production by OVA-Sensitized Splenocytes in Vitro To further investigate the mechanism by which M-16V suppresses the Th2 immune response and IgE production, we studied the effects on cytokines and $\mathrm{IgE}$ production when using various concentrations of heat-killed M-16V in vitro. Results indicated that M$16 \mathrm{~V}$ suppressed the OVA-induced total IgE and IL-4 production and induced secretion of IFN- $\gamma$ and IL-10 in OVA-immunized splenocytes in a dose-dependent manner (Figs. 3a$\mathrm{c}, \mathrm{e})$. TGF- $\beta$ was not markedly affected by the addition of M$16 \mathrm{~V}$ (Fig. 3f). Although lactic acid bacteria, such as L. rhamnosus and S. thermophilus, significantly induced IL-12p70, $\mathrm{M}-16 \mathrm{~V}$ was not able to induce IL-12p70 (Fig. 3d). These results were consistent with our previous report, ${ }^{23)}$ which demonstrated that the probiotic strain, Bifidobacterium longum BB536, tended to induce lower levels of the Th1inducing cytokines, such as IL-12 and INF- $\gamma$, as compared to that seen for lactobacilli and streptococci.

The present results showed that M-16V induced IL-10 production in a dose-dependent manner. Increasing evidence suggests that IL-10 and TGF- $\beta$ act as regulatory cytokines and play a critical role in maintaining homeostasis under the coexistence of commensal enteric bacteria. ${ }^{24)}$ We found that increased dose of M-16V $(100 \mu \mathrm{g} / \mathrm{ml})$ induced significantly higher level of IL-10, but completely failed to induce IFN- $\gamma$, although suppression of IL-4 and IgE was not altered (data not shown). Several studies have shown that probiotic strains can induce IL-10 and/or TGF- $\beta$ production via the splenocytes or Peyer's patch (PP) cells of probiotic-treated mice. ${ }^{17,18)}$ Fujii et al. ${ }^{25)}$ reported that the administration of $\mathrm{M}$ $16 \mathrm{~V}$ enhanced TGF- $\beta$ signaling through the regulation of Smad7 expression in preterm infants. However, the oral administration of M-16V to OVA-immunized mice did not enhance the ex vivo IL-10 or TGF- $\beta$ production by OVA-stimulated splenocytes (Fig. 2b). Due to experimental constraints, we were not able to determine the ex vivo production of these regulatory cytokines by OVA-stimulated PP cells. In addition, the high background of TGF- $\beta$ levels in the cell culture media in the present in vitro and ex vivo experiments on splenocytes may have interfered with the detection of possible differences between the treatment and control groups. The exact role of IL- 10 and TGF- $\beta$ production in the antiallergic activity of $\mathrm{M}-16 \mathrm{~V}$ remains unclear. Therefore, further studies are needed in order to be able to evaluate the details of the M-16V mechanism of suppression of the Th2 immune response and IgE production.

$B$. breve is one of the most dominant bifidobacteria in the infant microbiota. Strain M-16V was obtained from the fecal sample of a healthy baby. It has been shown to be effective in promoting the colonization of bifidobacteria and the formation of normal intestinal microbiota in low birth weight infants. ${ }^{26,27)}$ Oral administration of M-16V has also been demonstrated to be effective in promoting the formation of a bifidobacterial predominant flora, and in very low birth weight infants, may be prophylactic against severe infections 

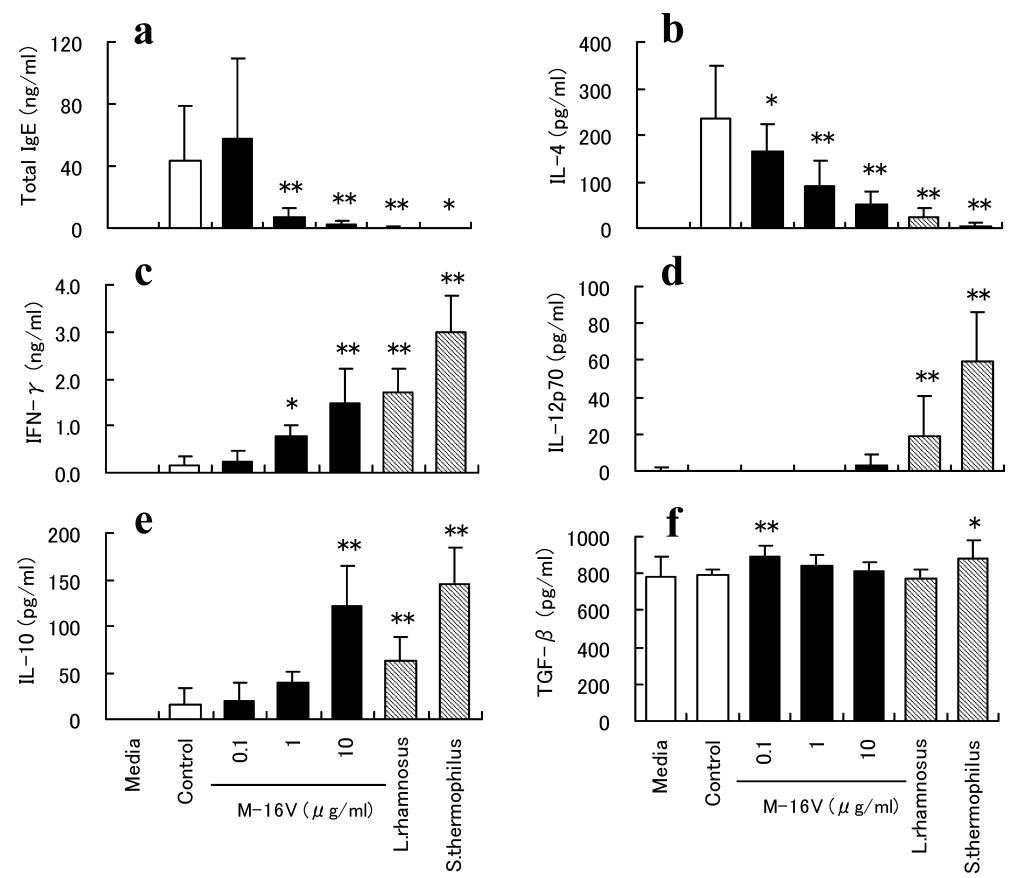

Fig. 3. Effect of Heat-Killed Bacteria on OVA-Induced Total IgE and Cytokine Production by OVA-Immunized Splenocytes

Splenocytes from OVA-sensitized mice were cultured with $100 \mu \mathrm{g} / \mathrm{ml}$ OVA in the absence (control) or presence of heat-killed bacterial cells (Bifidobacterium breve M-16V was $0.1-10 \mu \mathrm{g} / \mathrm{ml}$ and L. rhamnosus and S. thermophilus were $1 \mu \mathrm{g} / \mathrm{ml}$ ). The levels of total IgE (a) on day 14, IL-4 (b), IFN- $\gamma$ (c), IL-12p70 (d) and TGF- $\beta$ (f) on day 7 and IL-10 (e) on day 2 in the supernatants were measured by ELISA. Data are shown as mean \pm S.D. of three independent experiments. Significant differences as compared to control $(* p<0.05$, $* * p<0.01)$ were tested by ANOVA followed by Bonferroni multiple comparisons test.

caused by abnormal intestinal bacteria such as methicillinresistant Staphylococcus aureus (MRSA). ${ }^{28)}$ The antiallergic potential of this strain has also been demonstrated in studies on infants. ${ }^{20,21,25)}$ The present study also showed that M-16V modulated the systemic Th1/Th2 balance and suppressed the IgE production in both the in vitro and in vivo experiments. This supports previous studies that have reported finding on antiallergic effects in humans. Therefore, M-16V may be a promising candidate as a probiotic that can be used as a prophylactic treatment in allergic diseases, especially in infants.

\section{REFERENCES}

1) Lee B. W., Geha R. S., Leung D. Y., Pediatr. Clin. North Am., 35, 953-967 (1988)

2) Romagnani S., Curr. Opin. Immunol., 6, 838-846 (1994).

3) Stavnezer J., Curr. Opin. Immunol., 8, 199-205 (1996).

4) Kapsenberg M. L., Jansen H. M., Bos J. D., Wierenga E. A., Curr. Opin. Immunol., 4, 788-793 (1992).

5) Kidd P., Altern. Med. Rev., 83, 223-246 (2003).

6) Isolauri E., Arvola T., Sütas Y., Moilanen E., Salminen S., Clin. Exp. Allergy, 30, 1604-1610 (2000).

7) Kalliomaki M., Salminen S., Arvilommi H., Kero P., Koskinen P., Isolauri E., Lancet, 357, 1076-1079 (2001).

8) Viljanen M., Savilahti E., Haahtela T., Juntunen-Backman K., Korpela R., Poussa T., Tuure T., Kuitunen M., Allergy, 60, 494-500 (2005).

9) Ishida Y., Nakamura F., Kanzato H., Sawada D., Hirata H., Nishimura A., Kajimoto O., Fujiwara S., J. Dairy Sci., 88, 527-533 (2005).

10) Peng G. C., Hsu C. H., Pediatr. Allergy Immunol., 16, 433-438 (2005).

11) Xiao J. Z., Kondo S., Yanagisawa N., Takahashi N., Odamaki T., Iwabuchi N., Miyaji K., Iwatsuki K., Togashi H., Enomoto K., Enomoto T., Clin. Exp. Allergy, 36, 1425-1435 (2006).

12) Matsuzaki T., Yamazaki R., Hashimoto S., Yokokura T., J. Dairy Sci., 81, 48-53 (1998).

13) Shida K., Makino K., Morishita A., Takamizawa K., Hachimura S.,
Ametani A., Sato T., Kumagai Y., Habu S., Kaminogawa S., Int. Arch. Allergy Immunol., 115, 278-287 (1998).

14) Fujiwara D., Inoue S., Wakabayashi H., Fujii T., Int. Arch. Allergy Immunol., 135, 205-215 (2004).

15) Ohno H., Tsunemine S., Isa Y., Shimakawa M., Yamamura H., Biol. Pharm. Bull., 28, 1462-1466 (2005).

16) Sashihara T., Sueki N., Ikegami S., J. Dairy Sci., 89, 2846-2855 (2006).

17) Torii A., Torii S., Fujiwara S., Tanaka H., Inagaki N., Nagai H., Allergol. Int., 56, 293-301 (2007).

18) Nonaka Y., Izumo T., Izumi F., Maekawa T., Shibata H., Nakano A. Kishi A., Akatani K., Kiso Y., Int. Arch. Allergy Immunol., 145, 249257 (2008).

19) Segawa S., Nakakita Y., Takata Y., Wakita Y., Kaneko T., Kaneda H., Watari J., Yasui H., Int. J. Food Micobiol., 121, 1-10 (2008).

20) Hattori K., Yamamoto A., Sasai M., Taniuchi S., Kojima T., Kobayashi Y., Iwamoto H., Namba K., Yaeshima T., Arerugi, 52, 20-30 (2003).

21) Taniuchi S., Hattori K., Yamamoto A., Sasai M., Hatano Y., Kojima T., Kobayashi Y., Iwamoto H., Yaeshima T., J. Appl. Res., 5, 387-396 (2005).

22) Sato Y., Akiyama H., Suganuma H., Watanabe T., Nagaoka M., Inakuma T., Goda Y., Maitani T., Biol. Pharm. Bull., 27, 978-984 (2004).

23) Iwabuchi N., Takahashi N., Xiao J., Miyaji K., Iwatsuki K., Microbiol. Immunol., 51, 649-660 (2007).

24) Ruiz P. A., Shkoda A., Kim S. C., Startor R. B., Haller D., J. Immunol., 174, 2990-2999 (2005).

25) Fujii T., Ohtsuka Y., Lee T., Kudo T., Shoji H., Sato H., Nagata S., Shimizu T., Yamashiro Y., J. Pediatr. Gastroenterol. Nutr., 43, 83-88 (2006).

26) Li Y., Shimizu T., Hosaka A., Kaneko N., Ohtsuka Y., Yamashiro Y., Pediatr. Int., 46, 509-515 (2004).

27) Akiyama K., Hosono S., Takahashi E., Ishizeki S., Takigawa I., Imura S., Yamauchi K., Yaeshima T., Hayasawa H., Shimamura S., Acta Neonat. Jpn., 30, 130-137 (1994).

28) Akiyama K., Tauchi M., Ishizeki S., Yamauchi K., Yaeshima T., Hayasawa H., Shimamura S., J. Jpn. Soc. Premature Newborn Med., 8, 59-64 (1996). 